publishing industry.

"Our motivation is that when scientists and scholars are doing research that is non-classified and non-proprietary, and for the purpose of the public good, we want to do everything possible to make sure that is a public resource and not public property," says Brown. PLoS hopes to eventually compel other journals to also make research articles freely accessible.

"I think a lot of journals would follow," says Nicholas Cozzarelli, executive editor of the Proceedings of the National Academy of Sciences, a not-forprofit journal. In fact, he adds, PNAS considered allowing free access to all articles, but under its current subscriber-driven model, the journal would have lost too much revenue. "We would have needed an angel," he says.

Cozzarelli, who has advised PloS and is on its board, says he is taking a waitand-see approach to the author-driven model. For now, PNAS archives are available free of charge after 6 months, and Science's are available after a year.

For the PLoS journals, authors will be charged about $\$ 1,500$ per article (the fee may be waived under special circumstances) and will retain copyright. All content will be freely available on the web, with a fee for the print version. Siegel says she will hire a staff of professional editors, and is considering

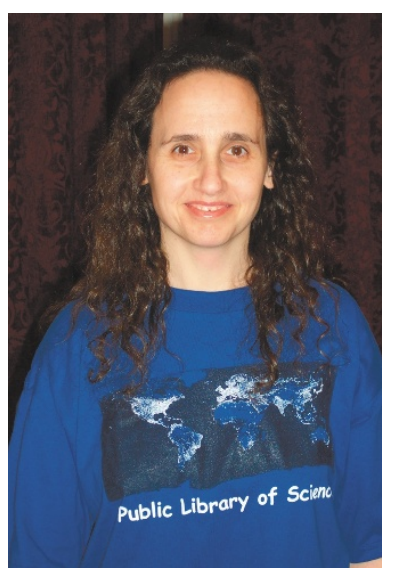

Vivian Siegel takes up idealism lion-dollar grant from the Gordon and Betty Moore foundation. It has also garnered other support. For example, the Howard Hughes Medical Institute has pledged to pay author fees to PLoS and similar journals for its investigators, according to HHMI vice president Gerry Rubin, who was the first author to publish in the free-access Journal of Biology.

Anyone who is interested in how PLoS fares in financing the journals can review the information on its websending every paper to at least one outside expert for review.

PLoS now has a five-year, nine-mil- site, says Brown. "This is a very public experiment."

Charlotte Schubert, New York

\title{
Finding a funding niche
}

In mid-December 2002, the American Foundation for AIDS Research (amfAR), a small private organization in New York, held an invitation-only "think tank" to decide how best to fund AIDS research without stepping on the toes of the National Institutes of Health (NIH). If the bleak budget predictions for science in the United States are confirmed, organizations such as amFAR will have an even greater task filling gaps left by the federal funding agencies.

Even in the best of times, the NIH, primarily through the National Institute of Allergy and Infectious Diseases (NIAID), funds less than half of the applications it receives for HIV and AIDS research. AmFAR and others pick up where the NIH leaves off, helping young researchers, clinical trials and esoteric projects not quite ready for prime time.

AmFAR, for instance, funds proposals from researchers "who have not had the long track record...or the preliminary data that's expected for an NIH proposal," says Jeffrey Laurence, senior scientist for programs at amfAR.

To avoid overlap, amfAR schedules grant reviews-with reviewers who also are on NIH panels-two weeks after NIH reviews. Carl Dieffenbach, associate director of basic science at NIAID, attended the think tank to add the NIH perspective.

The Elizabeth Glaser Pediatric AIDS Foundation (EGPAF) in Santa Monica, California, which focuses on AIDS in children, is also not interested in competing with the NIH or with amfAR, says Jeffrey T. Safrit, the organization's senior programs officer.

Instead, the foundation focuses on concepts "that are novel and wouldn't tend to get funded by the government," says Safrit. To prevent duplication, EGPAF, too, includes NIH scientists on its review panels. And like amfAR, it focuses on young investigators or on projects with less preliminary data than would be required by the NIH. "We try to bring people up to a level so they can compete successfully for NIH grants," Safrit says.

Such small organizations are not exclusive to AIDS research. The International Myeloma Foundation (IMF) in North Hollywood, California, is a patient advocacy and education organization that also funds small
$(\$ 40,000$ or $\$ 80,000)$ grants, particularly for young researchers and translational research. "One niche that the IMF stands by is the continued commitment to recognize and bring up through the ranks new and young researchers interested in myeloma," says Brian G. M. Durie, IMF chairman.

Even organizations with relatively large amounts of money, such as the International AIDS Vaccine Initiative (IAVI) in New York, work collaboratively with the NIH and pharmaceutical companies. IAVI's goal is to produce and distribute a vaccine to protect against HIV infection. "Normally, pharma companies would be the source of product development," says Seth Berkley, IAVI's president. "But in HIV vaccines, where there is a market failure, industry is not investing large amounts of shareholders' resources," he adds. "We strategically invest here."

Each organization has a unique approach to funding. AmfAR looks for "big impact"; IMF holds retreats for its scientific advisors; and IAVI sends scientists to major meetings to scout for ideas. Together, "what all of us are trying to get to is a more efficient system," says Dieffenbach. "The more that we share...the better each of us is equipped to move forward."

Myrna E. Watanabe, New York 